\title{
Investigation of $\mathrm{Ni}$ - and $\mathrm{Ti}-$ content influence on microstructure and phase transformation behavior of NiTi SMA alloyed with Ag
}

\author{
Gilberto Álvares da Silva ${ }^{1, a}$ and Jorge Otubo ${ }^{1}$ \\ ${ }^{1}$ ITASMART Group, Instituto Tecnológico de Aeronáutica, 12228-900, São José dos Campos, São Paulo, Brazil
}

\begin{abstract}
NiTi Shape Memory Alloys (SMA) became an interesting research field in metallurgy and physics, among many others, since its advent, back in 1960 's. Up to date, this interest remains due to the great range of unexploited research possibilities, in addition to the large number of application accessed by these alloys. Within those research possibilities, NiTi SMA has been used as the basis for new alloys by the introduction of a third, and even a forty, chemical element, what is called NiTi-based SMA. Silver addition was made via arc remelting to produce $\mathrm{Ni}_{54.99} \mathrm{Ti}_{43,01} \mathrm{Ag}_{2,00}$ and $\mathrm{Ni}_{52,99} \mathrm{Ti}_{45,01} \mathrm{Ag}_{2,00} \mathrm{wt}$ \%, so that silver acts as a substitute for $\mathrm{Ni}$ in Ti-rich, as well as a substitute for Ti in Nirich alloys, respectively; for comparison reasons, an alloy $\mathrm{Ni}_{53,99} \mathrm{Ti}_{44,01} \mathrm{Ag}_{2,00}$, with near-equiatomic Ni:Ti relationship, was melted. Remarks on metallurgy of ingot melting, microstructure developed and thermal properties of these alloys was accessed.
\end{abstract}

\section{Introduction}

The technology to stimulate different material properties (mechanical, thermal, electrical, etc.) as a result of scientific research, made metallic materials ceased to be essentially structural and started to be also functional materials. In this sense, the Shape Memory Alloys (SMA) comes out, among many others materials.

The fabrication of NiTi SMA is strictly related to the alloy properties, since chemical composition exerts great influence over the final properties of the alloy. Commonly, these alloys are produced by means of Vacuum Arc Remelting (VAR), Vacuum Induction Melting (VIM) and/or a combination of the methods. The $\mathrm{Ni}$ Ti relation in the alloy implies specifically temperatures transformations [1], and can be controlled by calculus of metallic charge to be melted, as well as by the melting procedure. The contaminants content can vary accordingly to the melting procedure used, and its influence on the properties of final alloy are seen through the presence of inclusions $\mathrm{TiC}, \mathrm{Ti}_{4} \mathrm{Ni}_{2} \mathrm{O}_{\mathrm{x}}[1,2]$; in very low concentrations, both $\mathrm{C}$ and $\mathrm{O}$ are present as interstitial and do not have great importance from the application point of view.

Despite applications of NiTi alloys ranges from biomedical to aerospace fields [3], there are a lot of applications unartful by its binary alloys solely. To broaden the applicability of these alloys, many alloying elements have been added to the binary, forming solid solutions, intermetallic compounds and/or precipitates in elemental form. In some areas, several applications are only reached by ternary alloys, however, often the gain in certain properties is accompanied by losses in others, or by increasing the cost of production. Anyway, NiTi-based ternary, and now, even on quaternary alloys are important and is in full development [4-6].

Since 2005, when the ternary NiTiAg shape memory alloy has proven to have SME/SE and an antibacterial action [7], this promising biomaterial has not been properly studied from a metallurgical point of view. To contribute to literature, a little bit poor about alloying NiTi

\footnotetext{
a Corresponding author: alvares@ita.br
}

with $\mathrm{Ag}$, this work brings data about the influence of $\mathrm{Ag}$ on NiTiAg alloys with different Ni:Ti relations. The ascast microstructures were observed, the present phases identified and the chemical compositions evaluated after the melting procedure. The transformation behavior upon heating and cooling was studied to disclose the relationship between chemical composition and transformation characteristics. In the face of the data, the behavior of as-cast NiTiAg ternary alloy with nearequiatomic Ni:Ti relation was discussed.

\section{Methods}

As the basis for adding Ag, was chosen a near-equiatomic NiTi alloy, from which was melted a high Ni content (Alloy 1) as well as a high Ti content alloy (Alloy 2), in addition to an alloy with Ni:Ti 1:1 (Alloy 3) (Table 1).All the NiTiAg alloys were calculated to have the same Ag content, 2\% in weight (approximately, 1\% atomic), what would enable to access the influence of the $\mathrm{Ni}$ and $\mathrm{Ti}$ content. The samples were melted in a laboratory-scale arc furnace with a non-consumable tungsten electrode and a water-cooled copper crucible, operating at $3 \mathrm{kV}$, under an Ar atmosphere of 750 mbar.

All the samples were melted and re-melted 3 times for enhanced chemical homogeneity and, then, solidified as ingots of circular cross-section with $10 \mathrm{~mm}$ diameter and $40 \mathrm{~mm}$ long. The as-cast ingots were weighted just after being cooled, and their masses compared with the initial mass of metallic charge. Initially, each metallic charge weights, approximately, $25 \mathrm{~g}$.

The sampling procedure of the as-cast ingots started with a cut along its cross section, using a low-speed saw with a BCN wafering blade. Samples for metallographic and x-ray diffraction analysis were that cross section samples, whereas the samples for DSC analysis were small pieces of 2,5 $\mathrm{mm} \times 2,0 \mathrm{~mm} \times 1,0 \mathrm{~mm}(1 \times \mathrm{w} \times \mathrm{t})$ with, approximately, $20 \mathrm{mg}$.

The microstructure of the NiTiAg SMA were studied using a Tescan Vega3 XMU Scanning Electron Microscopy (SEM). Its chemical composition was evaluated semi-quantitatively with an Energy Dispersive

This is an Open Access article distributed under the terms of the Creative Commons Attribution License 4.0, which permits unrestricted use distribution, and reproduction in any medium, provided the original work is properly cited. 


\section{MATEC Web of Conferences}

Spectroscopy (EDS) Oxford x-act $10 \mathrm{~mm}^{2}$ SDD detector. Particles measurements such as size, volume fraction and Feret diameter, were made in 15 images collected randomly in each sample, each one displaying an total area of $43 \times 10^{3} \mu^{2}$, with the aid of ImageJ (U.S. National Institutes of Health) software. X Ray Diffraction (XRD) analysis for phase identification was carried out in a Seifert-FPM URD 65 diffractometer using monochromatic $\mathrm{Cu}-\mathrm{k} \alpha$ radiation with a step scanning in $2 \theta$ range of $25-80^{\circ}$, at the room temperature. XRD data processing and diffraction peaks identification was made using Rigaku PDXL software. The phase transition behavior were studied by calorimetric analysis on a Netzsch 404c Pegasus DSC with $\mathrm{He}$ atmosphere for enhanced heat transfer, and cooling and heating rate of $10^{\circ} \mathrm{C} / \mathrm{min}$.

\section{Results}

In spite of the antibacterial action of NiTiAg has been proved, its development as a biomaterial are still hampered by production issues [7,8]. Alloying NiTi with $\mathrm{Ag}$, a kind dissimilar element from those of the original alloy, is a challenge for who are dealing with production. However, from the metallurgical point of view, there is a wide field on NiTiAg ternary system to be explored, since questions about alloy fabrication, silver effect on transformation behavior, performance under thermomechanical process and many others, remains.

Among all this system elements, silver is the one with higher vapor pressure. Depending on the pressure inside the furnace chamber, silver will boil just before, or at the same time Ti are melting. Matsumoto [9] realize this issue when tried to add silver to a NiTi alloy by Electron Beam Melting (EBM).

The arc melting procedure has the advantage to be enabled under a wide range of chamber pressures, from the low vacuum to pressures higher than the atmospheric. Taking this advantage, is possible to melt the feedstock under a chamber pressure higher than the vapor pressure of any element that compose the metallic charge, reducing problems of metal loss.

Far from the process performance to melt NiTi SMA's properly, there is a chemical problem, which makes the melting so challenging, contributes to reduce the metal yielding on final alloy, but rarely is considered. Ti and $\mathrm{Ni}$ react together, under an exothermic combustion reaction, releasing great amount of heat $\left(\Delta H=-67 \mathrm{~kJ}_{\mathrm{mol}} \mathrm{mol}^{-1}\right)$. The reaction occurs at the surface of the material, so when that great amount of enthalpy is suddenly released, the local temperature at the charge sharply rises to higher than $1700^{\circ} \mathrm{C}[10]$. Depending on the pressure inside the furnace chamber, the silver element can boil from the charge at this temperature. This situation can even be worse if the heat from the electric arc is accounted, and to be honest, the worst situation is what really occurs, leading to the lost both $\mathrm{Ni}$ and $\mathrm{Ti}$.

The material lost by evaporation during the melting, once in contact with the cooled chamber surface, solidifies in spherical-shapes. Analyzing these particles, was possible to identify all the metals that compose the system, i.e., not only Ag are lost.

The analysis of these materials recovered from the furnace are beyond the scope of this paper. However, a simple calculus can be made, which corroborate the affirmation that not only Ag are lost. Comparing the mass of the metallic charge, and the mass of the ingot after the melting procedure, the variation was, approximate, $0,8 \%$ in weight. Evaluating the silver content on each alloy (Table 1) is possible to see that the silver yielding of the melting procedure in an arc furnace was up to $80 \%$. Accounting the silver that was not in the alloy $(0,4 \%$ in weight), one can conclude that $\mathrm{Ni}$ and $\mathrm{Ti}$ are lost in the procedure too.

The material losses during melting are one drawback of the procedure used; in addition the silver yielding was not as higher as that for $\mathrm{Ti}$ and $\mathrm{Ni}$. Nevertheless, the former is an intrinsic problem to the metallic system, which will be present in any melting procedure chosen, while the latter is a problem that can be even worst in melting procedures that uses high vacuum.

Table 1: Aimed and measured chemical composition for NiTiAg alloys melted.

\begin{tabular}{|c|c|c|c|}
\hline \multirow{2}{*}{ Samples } & \multicolumn{3}{|c|}{ Aim Composition [wt.\%] } \\
\hline & $\mathrm{Ni}$ & $\mathrm{Ti}$ & $\mathrm{Ag}$ \\
\hline Alloy 1 & 54,99 & 43,01 & 2,00 \\
\hline Alloy 2 & 52,99 & 45,01 & 2,00 \\
\hline Alloy 3 & 53,99 & 44,01 & 2,00 \\
\hline \multirow{2}{*}{ Samples } & \multicolumn{3}{|c|}{ Measured Composition [wt.\%] } \\
\hline & $\mathrm{Ni}$ & $\mathrm{Ti}$ & $\mathrm{Ag}$ \\
\hline Alloy 1 & $53,8 \pm 0,3$ & $44,4 \pm 0,1$ & $1,6 \pm 0,1$ \\
\hline Alloy 2 & $51,9 \pm 0,1$ & $46,6 \pm 0,1$ & $1,6 \pm 0,1$ \\
\hline Alloy 3 & $53,3 \pm 0,4$ & $45,4 \pm 0,4$ & $1,5 \pm 0,2$ \\
\hline
\end{tabular}

\subsection{Macro and Microstructural Analysis}

The macrostructures produced by lab-scales arc melting furnaces are quite dependent of the cooling system available on the furnace and differ from the industrialscale furnaces, primarily, due to its low production capacity. Despite of it, the high cooling rate promoted by the water-cooled copper hearth enables reduced microsegregation, rapid solidification but not amorphization. Figure 1a shows columnar grains that grow from the interface bath/hearth, while Figure $1 \mathrm{~b}$ shows nearequiaxial grains present at the top portion of the ingot.

On the bottom section of the ingot, one can see millimeter-sized columnar grains, which are nucleated immediately on the solidification, so that no chilled zone are visible (Fig. 1a). Those columnar grains grow up to the upper region of the ingot, where there is a transition to near-equiaxial grains. The solidification mechanism are changed due to the heat extraction which flows from the 
bottom to the top (the bottom are in contact with the cooled crucible, while the top portion has its heat extracted just by the convection of the argon atmosphere just above it). Under lower heat extraction rates, equiaxial grain growth are more prone to occur. All the three alloys melted in this work present these characteristic macrostructures.

Another common feature for all NiTiAg is its homogenous silver particles distribution all over the ingot; those macrographs (Fig. 1a and b) are also useful to see its random distribution. This homogeneity is required since the Ag particles are responsible for the antibacterial effects, and is the guarantee that the whole sample experiences the same effect due to silver addition. The remelting procedures are accounted as the responsible for this homogeneity.
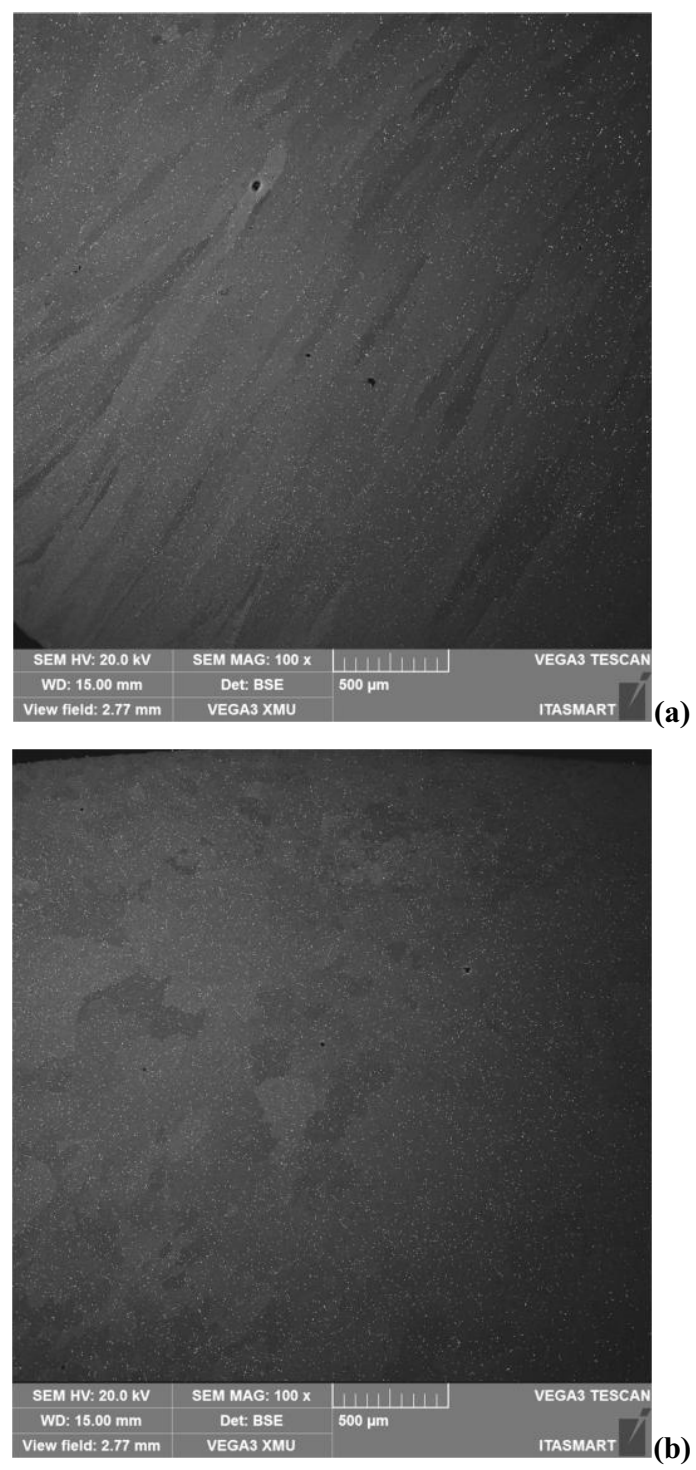

Figure 1: Characteristic macrostructure of the bottom (a) and the top (b) of NiTi2Ag ingots.

Like the macro, the microstructures of NiTiAg with high $\mathrm{Ni}$, high $\mathrm{Ti}$ and Ni:Ti near-equiatomic relation are quite similar too. For all, three mainly constituents can be identified: (i) a NiTi matrix, which contain a small quantity of silver in solid solution; this value was estimated in $0.26 \%$ wt.\% [19]; (ii) silver particles homogeneously dispersed with sizes ranging from nano to micrometers, bright spots in Figure $1 \mathrm{a}-\mathrm{b}$ and 2; (iii) $\mathrm{Ti}_{2}(\mathrm{Ni}, \mathrm{Ag})$ phase, an originally $\mathrm{Ti}_{2} \mathrm{Ni}$ phase formed locally due to the proportion of $\mathrm{Ti}$ and $\mathrm{Ni}$ in the bath and the solidification procedure (Fig. 3).

Silver particles with different sizes can be seen in all alloys microstructures, and generally the larger particles are located at grain boundary regions, and on bottom position of ingot cross section. It is explained by the solidification process, in which the solute ( $\mathrm{Ag})$ concentrates in front of the solid-liquid (S/L) interface.

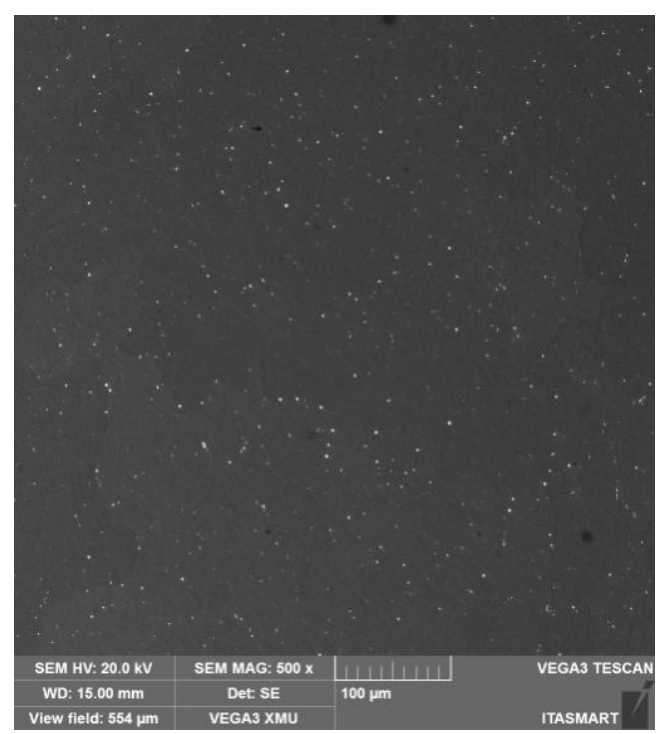

Figure 2: Microstructure for NiTi2Ag alloys.

Table 2 gives data on particles measurements for all alloys melted. The size of silver particles are almost a micron, however great deviation was found. This variation in particles size are due to the size differences regarding the ingot cross section position in which they are, i.e., at the bottom, at center or on top of cross section. This position influence are attributed to the solidification process experienced: an non-equilibrium solidification with a dendritic interface and solute $(\mathrm{Ag})$ rejection to the front of solid/liquid $\mathrm{S} / \mathrm{L}$ interface. In addition, once silver has larger specific mass and its content are higher than the solubility limit, this element is draw off to the bottom position, when in the liquid state. Due to the high velocity of $\mathrm{S} / \mathrm{L}$ interface, the solidification at the bottom, and even at the center of ingot cross section, occurs at high rates, and that silver amount on liquid state are promptly enclosed by NiTi solid, formed around $1310^{\circ} \mathrm{C}$. As result, larger silver particles are found in these regions. Otherwise, at the top position, in spite of casting occurs bringing rejected silver from lower position (the S/L interface movement), at this time lower silver content are available on alloy, and therefore a smaller silver particles are found at the top. I Detailed data on ingot position influence over silver particles size are under analysis, since it is important to antibacterial effect expected from this alloys, and will published elsewhere.

Regarding the volume fraction of silver particles, the near-equiatomic alloy (Alloy 3 ) shows the higher value, 
what is in agreement with the mean particle size data. The Feret diameter, with low deviations, shows that silver particles are almost spherical in shape; Circularity (ImageJ) data was generated along with Feret diameter and is in agreement, however it was hidden here.

Table 2: $\mathrm{Ag}$ and $\mathrm{Ti}_{2}(\mathrm{Ni}, \mathrm{Ag})$ particle measurements.

\begin{tabular}{lccc}
\hline & \multicolumn{3}{c}{ Measurements } \\
\cline { 2 - 4 } Particle & $\begin{array}{c}\text { Mean } \\
\text { Particle } \\
\text { Size }[\mu \mathrm{m}]\end{array}$ & $\begin{array}{c}\text { Volume } \\
\text { Fraction } \\
{[\%]}\end{array}$ & $\begin{array}{c}\text { Mean Feret } \\
\text { Diameter } \\
{[\mu \mathrm{m}]}\end{array}$ \\
\hline Alloy 1 & & & \\
$\mathrm{Ag}$ & $0,992 \pm 0,274$ & $0,961 \pm 0,308$ & $1,351 \pm 0,176$ \\
$\mathrm{Ti}_{2}(\mathrm{Ni}, \mathrm{Ag})$ & $0,533 \pm 0,236$ & $0,774 \pm 0,086$ & $1,151 \pm 0,285$ \\
Alloy 2 & & & \\
$\mathrm{Ag}$ & $0,923 \pm 0,028$ & $0,839 \pm 0,085$ & $1,188 \pm 0,022$ \\
$\mathrm{Ti}_{2}(\mathrm{Ni}, \mathrm{Ag})$ & $2,872 \pm 0,223$ & $3,791 \pm 0,201$ & $2,616 \pm 0,364$ \\
Alloy 3 & & & \\
$\mathrm{Ag}_{\text {Ti }}(\mathrm{Ni}, \mathrm{Ag})$ & $0,512 \pm 0,202$ & $0,781 \pm 0,192$ & $1,088 \pm 0,199$ \\
\hline
\end{tabular}

$\mathrm{Ti}_{2}(\mathrm{Ni}, \mathrm{Ag})$ phase are present in all alloys (Table 2) and the presence of silver as a substitute for $\mathrm{Ni}$ in this phase is shown in Table 3, measured by EDS semi-quantitative analysis. This phase, originated from chemical composition unbalances, are located at interdendritic regions, mainly due to it solidification temperature (approximately, $1250^{\circ} \mathrm{C}$ ). From this perspective, one can see that it might work as subtracts for nucleation of silver particles.

Table 3: $\mathrm{Ti}_{2} \mathrm{Ni}$ and $\mathrm{Ti}_{2}(\mathrm{Ni}, \mathrm{Ag})$ phase composition.

\begin{tabular}{lccc}
\hline \multirow{2}{*}{ Particles } & \multicolumn{3}{c}{ Chemical Composition [wt.\%] } \\
\cline { 2 - 4 } & $\mathrm{Ni}$ & $\mathrm{Ti}$ & $\mathrm{Ag}$ \\
\hline $\begin{array}{l}\mathrm{Ti}_{2} \mathrm{Ni} \\
\text { (theoretical) }\end{array}$ & 37,99 & 62,01 & - \\
$\begin{array}{l}\mathrm{Ti}_{2}(\mathrm{Ni}, \mathrm{Ag}) \\
\text { (measured) }\end{array}$ & 36,8 & 62,1 & 1,1 \\
\hline
\end{tabular}

Re-melting steps were made in order to promote hot metal stirring to achieve homogeneity in global chemical composition and on silver particles distribution. In spite of all alloys present $\mathrm{Ti} 2(\mathrm{Ni}, \mathrm{Ag})$ phase, it can be said that the re-melting steps were efficient to homogenization, since this intermetallic phase cannot be removed completely from any NiTi alloy (just compare the data for Alloy 1 and 3), and, as expected, just that alloy with high $\mathrm{Ti}$ content (Alloy 2) shows increased volume and particle size for this phase.

To give information about the phases on each sample, XRD analysis was employed, and the resultant diffractogram are shown in Figure 4.

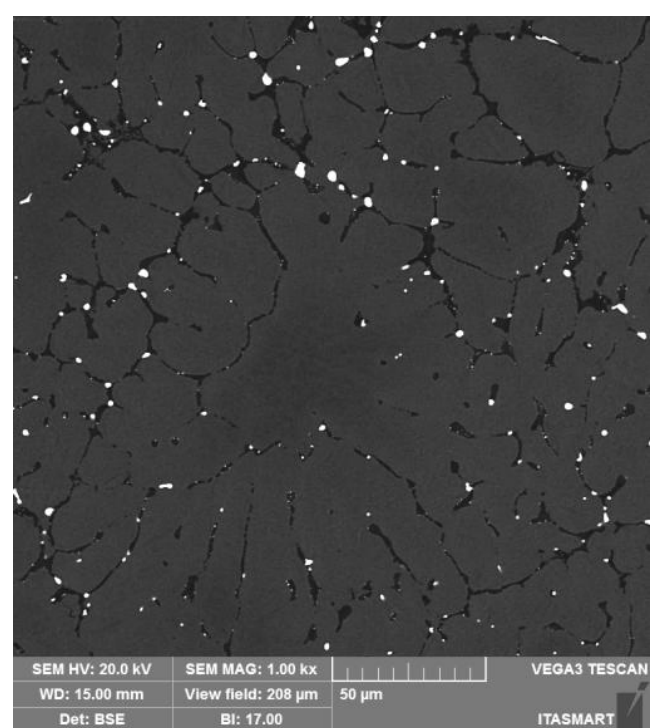

Figure 3: $\mathrm{Ti}_{2}(\mathrm{Ni}, \mathrm{Ag})$ phase on interdentric region of a high $\mathrm{Ti}$ content NiTiAg alloy (Alloy2).

The first sight of all alloys is that silver peaks could not be identified; explanation may be due to the low silver content of the alloys (approximately, $1 \%$ atomic), then the low phase volume fraction in microstructure (Table 2), small enough to not be detected by common XRD measurements. In martensitic alloys, the high intensity peak for silver element would be overlapped by (002) peak of martensite.

Alloy 1, that with high $\mathrm{Ni}$ content, shows just characteristics peaks for NiTi austenite phase. The (110) peak can lead to conclude that this alloy is on austenitic thermodynamic state at room temperature, what would be expected for a high $\mathrm{Ni}$ content $\mathrm{NiTi}$ alloy at this temperature. In Alloy 2, just martensitic characteristic peaks were found, as well as in Alloy 3. These data agree with calorimetric data (Fig. 5).

Ti2(Ni,Ag) peaks cannot be identified, even on alloy 2 (high Ti content). The characteristics peaks for this phase are probably overlapped by (012) peaks of martensite.

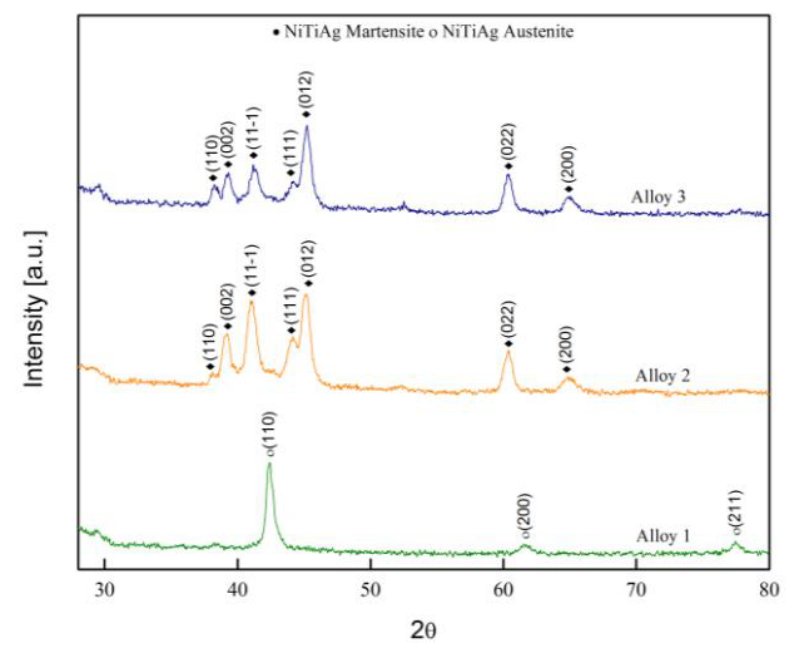

Figure 4: X-Ray Diffraction data for NiTi2Ag alloys 


\subsection{Phase transformation Behavior}

The transformation behavior upon heating and cooling of NiTiAg alloy is great controversial in literature. Some authors define the silver as a martensite stabilizer [7], while other defines it as a martensite suppressor [8].

Its established that the higher the Ni content, the lower the characteristic temperatures. The silver element was proved to influence the same way when alloying NiTi, however less powerful [11]. Among the samples under study, only the Alloy 1 does not show any phase transformation (Figure 5). It is believed that combined effects of $\mathrm{Ni}$ and $\mathrm{Ag}$ acts on this sample, drastically reducing the transformation temperatures.

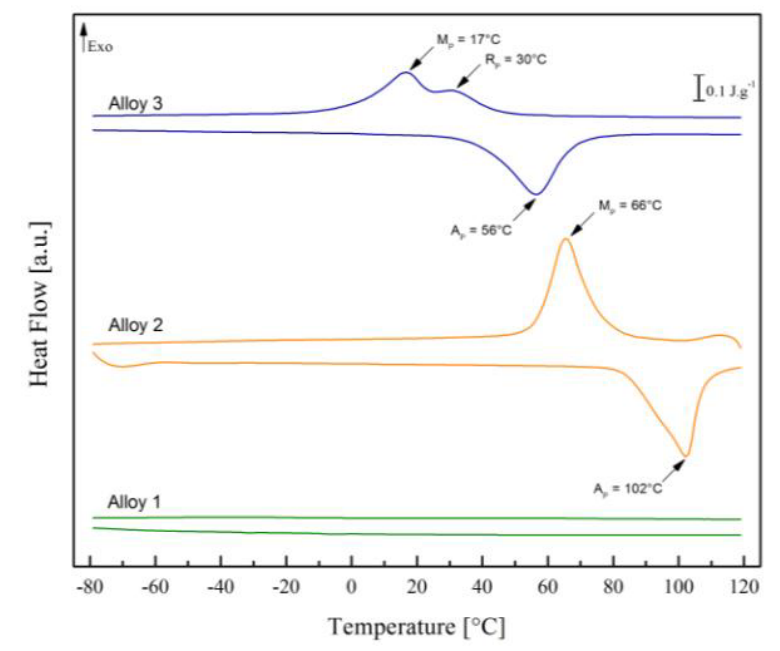

Figure 5: DSC chart for Ni-rich, Ti-rich and N.E. NiTi2Ag alloys.

Despite higher nickel contents reduce transformation temperatures, lower nickel contents (or higher titanium contents) do not increase that. Ti-rich alloys shows multistage behavior, both on cooling and on heating, as it main feature [12]. Alloy 2 cannot be considered a Ti-rich alloy, and its behavior on calorimetric analysis proves it; just a single-stage phase transformation was found. Besides, for Alloy 2 all the characteristics temperatures was raised, a completely different behavior in comparison with other alloys (Table 4). Complex relationship between chemical composition, present phases and particles sizes should be explored in order to provide any insight on the mechanism for increased temperatures, once the austenite-stabilizer action of silver was completed neglected. Its necessary also consider the formation of Ti$\mathrm{Ag}$ intermetallic phases, such as TiAg and TiAg2 on nanoscale. Its scenario is completely undiscovered until today and would be explored in future.

Alloy 3 experience a multiple-stage phase transition, commonly found on ternary NiTiX $(\mathrm{X}=\mathrm{Fe}, \mathrm{Cr}, \mathrm{Al})$ and characteristics temperatures lower than Alloy 2. A prominent R-phase peak are found even on as-cast NiTiAg alloys with near-equiatomic Ni:Ti relation with Ag content higher than $2 \%$ in weight [11]. By comparison between Alloy 2 and 3, this first insight shows that can be possible to raise the transformation temperatures by increasing Ti content on the NiTiAg ternary system.
The silver particles as well as the sliver element in solid solution affect the phase transition kinetic, what can be seen for Alloy 2 and Alloy 3 on DSC chart (Fig. 5). Both are believed to increase the nucleation barrier, then hamper the phase transformation by inducing stress on lattice, being necessary greater cooling or heating to surpass it. It is believed that $\mathrm{Ti}-\mathrm{Ag}$ precipitates can also act in nanoscale.

The hysteresis of Alloy 2 and 3 have values close to that for NiTi alloys, as well as the latent heats involved in phase transformation (Table 4). It can be seen as good results if one imagine increase the temperatures transformation by adding $\mathrm{Ti}$ and $\mathrm{Ag}$ on NiTi system.

Table 4: Characteristics temperatures, hysteresis and latent heat of produced alloys.

\begin{tabular}{|c|c|c|c|c|c|c|c|c|}
\hline & \multicolumn{8}{|c|}{ Measurements } \\
\hline & $\mathrm{A}_{\mathrm{s}}$ & $A_{f}$ & $\mathrm{M}_{\mathrm{s}}$ & $\mathrm{M}_{\mathrm{f}}$ & $\mathrm{R}_{\mathrm{s}}$ & $\mathrm{R}_{\mathrm{f}}$ & $\mathrm{H}$ & $Q$ \\
\hline $\begin{array}{l}\text { Alloy } \\
1\end{array}$ & - & - & - & - & - & - & - & - \\
\hline $\begin{array}{l}\text { Alloy } \\
2\end{array}$ & 83 & 109 & 79 & 55 & - & - & 29 & $\begin{array}{l}31,7 / \\
28,4\end{array}$ \\
\hline $\begin{array}{l}\text { Alloy } \\
3\end{array}$ & 41 & 67 & 26 & 5 & 39 & 29 & 32 & $\begin{array}{l}29,9 / \\
25,74\end{array}$ \\
\hline
\end{tabular}

\section{Conclusions}

The conclusions are presented as the followings:

1. Arc melting can be used to melt NiTiAg SMA's. The material losses are acceptable: $\mathrm{Ni}$ and $\mathrm{Ti}$ losses are intrinsic to the melting of these elements, while the Ag lost can be reduced using relative high pressure inert atmospheres on furnace chamber.

2. The macrostructure and microstructures of the as-cast samples are quite similar, and the $\mathrm{Ni}$ and Ti-content do not exert any influence over it. Columnar grains are present at the bottom and center positions of ingot, while near-equiaxial grains are predominantly at the top position. The microstructures are formed by dendritic NiTi phase, with some Ag in solid solution, pure silver particles and $\mathrm{Ti} 2(\mathrm{Ni}, \mathrm{Ag})$ phase on interdendritic regions.

3. On XRD analysis was identified austenitic NiTi phase for Alloy 1, and martensitic NiTi phase for Alloys 2 and 3. Due to the low volume fraction, peaks for silver and $\mathrm{Ti} 2(\mathrm{Ni}, \mathrm{Ag})$ were overlapped by NiTiAg peaks.

4. From DSC data was possible to conclude that $\mathrm{Ni}$ and $\mathrm{Ag}$ acts together lowering the phase transformation temperatures on alloy with high $\mathrm{Ni}$ content. On the other hand, the addition of Ti besides the equiatomic relation raises all these 
temperatures, and the silver seems not to affect in nothing in this case. For NiTiAg alloy with nearequiatomic $\mathrm{Ni}: \mathrm{Ti}$ relation a multistage transformation was found.

\section{References}

[1] J. Frenzel, E.P. George, A. Dlouhy, Ch. Somsen, M.F.X. Wagner, G. Eggler. Acta Mater. 58, 3444-3458 (2010).

[2] J. Frenzel, Z. Zhang, Ch. Somsen, K. Neuking, G. Eggler. Acta Mater. 55, 1331-1341 (2007).

[3] W. Predki, A. Knopik, B. Bauer. Mat. Sci. Eng. A 481-482, 598-601 (2008)

[4] O. Mercier and K.N. Melton, Met. Trans. 10A, 387 (1979).

[5] K.N. Melton, J. Simpson and T.W. Duerig, US Patent 4,144,057 (1988).
[6] O. Rios, R. Noebe, T. Biles, A. Garg, A. Palczer, D. Scheiman, H.J, Seifert, M. Kaufman. Proc. of Smart Structures and Materials (2005).

[7] K.T. Oh, U.H. Joo, G.H. Park, C.J. Hwang, K.M. Kim. J. Biomed. Mater. Res-A. 76, 306 (2006).

[8] Y.F. Zheng, B.B. Zhang, B.L. Wang, L. Li, Q.B. Yang, L.S. Cui. Acta Biomater. 7, 2758 (2011).

[9] H. Matsumoto. J. Mater. Sci. Lett. 44, 567 (1991).

[10] S.K. Sadrnezhaad and S. Badakhshan Raz. J. Mater Sci Technol. 21, 484 (2005).

[11] G. Álvares da Silva, J.E. Matieli and J. Otubo. Proc. of the International Conference on Shape Memory and Superelastic Technologies, 11 (2014).

[12] A.S. Paula, K.K. Mahesh, C.M.L. dos Santos, F.M. Braz Fernandes, C.S. da Costa Viana. Mater Sci Eng A 481-482, 146 (2008). 